Clinical Study

\title{
Predictors of first-line treatment persistence in a Portuguese cohort of relapsing-remitting multiple sclerosis
}

\author{
Inês Correia ${ }^{\mathrm{a}, *}$, Inês Brás Marques ${ }^{\mathrm{a}}$, Mário Sousa ${ }^{\mathrm{a}}$, Sónia Batista ${ }^{\mathrm{a}}$, Rogério Ferreira ${ }^{\mathrm{b}}$, Carla Nunes ${ }^{\mathrm{a}}$,

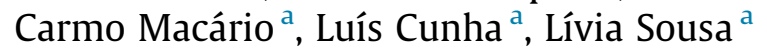 \\ a Neurology Department, Centro Hospitalar e Universitário de Coimbra, Praceta Prof. Mota Pinto, 3000-075 Coimbra, Portugal \\ ${ }^{\mathrm{b}}$ Internal Medicine Department, Centro Hospitalar e Universitário de Coimbra, Praceta Prof. Mota Pinto, 3000-075 Coimbra, Portugal
}

\section{A R T I C L E I N F O}

\section{Article history:}

Received 14 September 2015

Accepted 19 December 2015

Keywords:

Effectiveness

Injectable disease-modifying therapies

Relapsing-remitting multiple sclerosis

Treatment persistence

\begin{abstract}
A B S T R A C T
Treatment persistence in first-line injectable disease-modifying therapies (DMT) for relapsing-remitting multiple sclerosis (RRMS) is an important indicator of effectiveness. Identifying predictors of treatment discontinuation is important as there are other therapies currently available and a growing range of emerging drugs. We report a retrospective study of RRMS and clinically isolated syndrome patients followed in a University Hospital during a 13-year period with the objective of identifying predictors of treatment persistence. An evaluation of persistence on the first DMT, rates of DMT discontinuation, and reasons and predictors of discontinuation was performed. A total of 410 patients were included, $69 \%$ female, with mean disease duration of 37.8 months, mean age of 34.2 years and mean follow-up time of 6.1 years. The first DMT was glatiramer acetate (GA) in $27.56 \%$ of patients, interferon (IFN) $\beta-1 \mathrm{a}$ intramuscular in $26.34 \%$, IFN $\beta-1 \mathrm{~b}$ in $26.10 \%$, IFN $\beta-1 \mathrm{a} 22$ in $13.66 \%$ and IFN $\beta-1 \mathrm{a} 44$ in $6.34 \%$. Treatment was discontinued in $16.34 \%$ of patients after 1 year of treatment and in $50.24 \%$ of patients in the total follow-up time, with a mean time for discontinuation of 39.80 months. Higher baseline Expanded Disability Status Scale score was an independent predictor of treatment discontinuation (hazard ratio $1.35, \mathrm{p}=0.002$ ). After the first year, treatment persistence was $90.74 \%$ for IFN $\beta-1$ a-IM, $88.46 \%$ for IFN $\beta-1 \mathrm{a} 44$, $83.18 \%$ for IFN $\beta-1 b, 83.19 \%$ for GA and $69.64 \%$ for IFN $\beta-1 \mathrm{a} 22$ ( $\mathrm{p}=0.014)$. Lower frequency of administration was associated with higher persistence rates. The most common reason for treatment discontinuation was lack of efficacy in all DMT subgroups.
\end{abstract}

(C) 2016 Elsevier Ltd. All rights reserved.

\section{Introduction}

Treatment effectiveness encompasses the effect of treatment under everyday conditions of care, resulting from a combination of efficacy, safety, tolerability and patient satisfaction. Therefore, treatment persistence is considered an important indicator of effectiveness.

Injectable disease-modifying therapies (DMT) were, until recently, the only first-line treatments approved for relapsingremitting multiple sclerosis (RRMS). In the pivot clinical trials of this drugs, the rates of DMT persistence at the end of first year ranged from $90 \%$ to $97 \%$ [1-4]. However, these results may not be adequately extrapolated to the real world population, as lower rates of treatment persistence have been reported in post-marketing studies, with real-world studies describing rates of treatment persistence from $78.5 \%$ to $90 \%$ after one year and dropping to $59 \%$ to

\footnotetext{
* Corresponding author. Tel.: +351 239400400.

E-mail address: mcorreia.ines@gmail.com (I. Correia).
}

$72 \%$ between the third and fifth year of treatment, with discontinuation occurring mainly due to side effects and lack of efficacy [5-8].

In this article, we present a retrospective study of RRMS and clinically isolated syndrome (CIS) patients with the objective of assessing treatment persistence for the first DMT and evaluating the reasons and possible predictors of treatment discontinuation.

\section{Materials and methods}

This is a retrospective study including patients with RRMS, according to McDonald Criteria of 2010, and CIS, followed in the multiple sclerosis (MS) outpatient clinic of a university hospital.

The study included treatment naïve patients who were started on first line DMT between 2000 and 2013. The following subgroups of DMT were used: glatiramer acetate (GA), Interferon (IFN) $\beta-1 \mathrm{a}$ intramuscular (IM), IFN $\beta-1 \mathrm{a} 22$, IFN $\beta-1 \mathrm{a} 44$ or IFN $\beta-1 \mathrm{~b}$.

Exclusion criteria included previous exposure to other treatments, including immunosuppressive drugs (such as azathioprine, mycophenolate mophetil, cyclophosphamide, mitoxantrone or 
methotrexate) and other DMT approved for RRMS (such as natalizumab, fingolimod or alemtuzumab), and previous inclusion in clinical trials.

Clinical evaluation of the patients was performed in the outpatient clinic with 6-month intervals and all the data collected was recorded in our MS consultation database using the program iMED $^{\circledR}$.

Data collected comprised demographic data, including sex, age at diagnosis and age at first treatment, clinical data, including disease duration, clinical presentation,relapses and disability score assessed by the Expanded Disability Status Scale (EDSS) and treatment data, including first DMT used and treatment adverse events. First DMT treatment persistence, defined as months of continuous use of the first DMT, and reasons for treatment discontinuation were assessed.

Treatment discontinuation due to lack of efficacy was defined by the treating physician in a standard manner, and considered when there was disability progression, relapses or increase in MRI lesion load. Treatment discontinuation due to adverse events was considered when treatment was stopped or switched due to important systemic or local reactions or infections. Pregnancy was considered a reason for treatment discontinuation in patients who stopped treatment because of pregnancy or while attempting conception.

Accurate annualized relapse rate previous to the first DMT was not available in many patients and therefore was not included in the analysis.

Demographic characteristics are presented as means and standard deviations for continuous variables, and as frequencies and percentages for categorical variables. Patient EDSS is described as mean and standard deviation.

In our sample all the variables have a non-normal distribution, except for age at MS diagnosis and age at DMT start, therefore nonparametric tests were used. Wilcoxon Signed Ranks Test was used to compare related samples, the Mann-Whitney Test to compare different groups of patients and multivariable survival analyses were used to identify predictors of treatment discontinuation. Statistical significance was considered when $\mathrm{p}<0.05$, and $95 \%$ confidence intervals $(\mathrm{CI})$ were used in the graphs. IBM SPSS Statistics ${ }^{\circledR}$ (version 20.0) (IBM, Armonk, NY, USA) was used for the statistical analysis.

\section{Results}

From a global population of 966 patients followed in our MS outpatient clinic, 410 RRMS and CIS treatment-naïve patients were started on a first line DMT between 2000 and 2013 and were included in the study.

\subsection{Patient demographics}

All the patients had Caucasian background, $68.54 \%(n=281)$ were female, the mean disease duration at treatment start was 37.8 months and the mean age at first treatment was 34.2 years. The mean follow-up time was $6.1 \pm 4.0$ years.

Table 1 presents more details about the patient demographics and also clinical presentation and EDSS at baseline.

The first treatment was glatiramer acetate (GA) in 113 patients (27.56\%), Interferon $\beta$ (IFN $\beta$ )-1a intramuscular (IFN $\beta$ - 1 aIM) in 108 patients (26.34\%), IFN $\beta-1 \mathrm{~b}$ in 107 patients (26.10\%), IFN $\beta-1 \mathrm{a} 22$ in 56 patients (13.66\%) and IFN $\beta-1 \mathrm{a} 44$ in 26 patients (6.34\%).

Comparing the DMT subgroups, it was noted a tendency to lower age at disease onset of GA patients $(31.17 \pm 10.54$ years, $\mathrm{p}=0.051)$ and a higher baseline EDSS in the IFN $\beta-1 \mathrm{~b}(2.56 \pm 1.12)$ and IFN $\beta-1 \mathrm{a} 22(2.33 \pm 0.98)$ subgroups $(\mathrm{p}<0.001)$ (Table 1$)$.

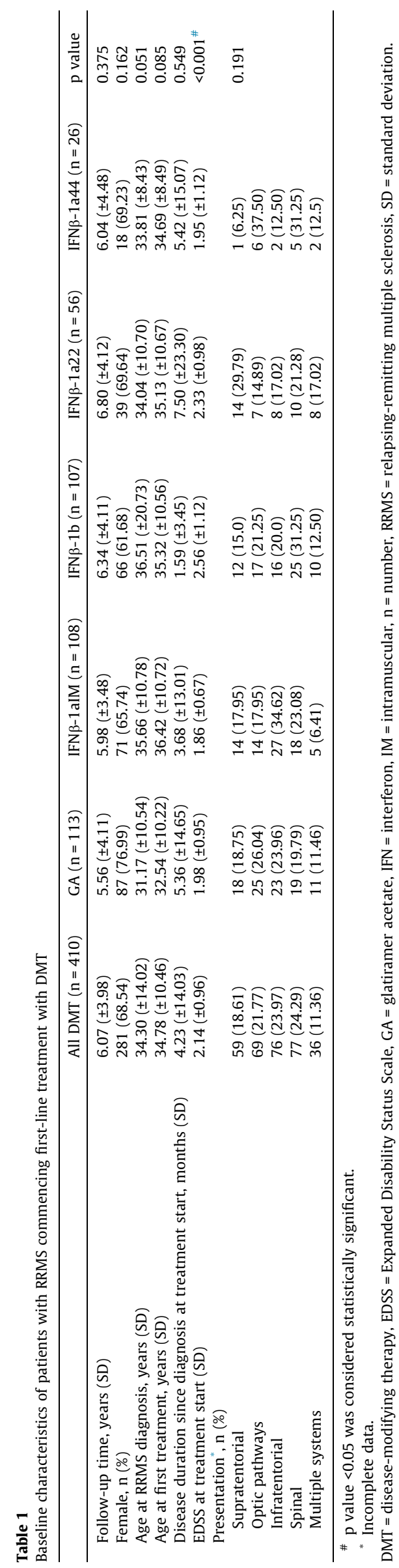


Table 2

Clinical characteristics of patients with RRMS commencing first-line treatment with DMT according to persistence on the first DMT

\begin{tabular}{|c|c|c|c|}
\hline & Persistence & Discontinuation & $\mathrm{p}$ value \\
\hline Female, n (\%) & $138(67.65)$ & $143(69.42)$ & 0.70 \\
\hline Age at RRMS diagnosis, years (SD) & $35.71( \pm 10.95)$ & $32.92( \pm 16.41)$ & $0.001^{\#}$ \\
\hline Age at first treatment, years (SD) & $36.78( \pm 10.62)$ & $32.79( \pm 9.94)$ & $0.020^{\#}$ \\
\hline $\begin{array}{l}\text { Disease duration since diagnosis at } \\
\text { treatment start, months (SD) }\end{array}$ & $4.52( \pm 14.93)$ & $3.94( \pm 13.11)$ & 0.993 \\
\hline EDSS at baseline, (SD) & $2.06( \pm 0.99)$ & $2.22( \pm 0.92)$ & $0.017^{\#}$ \\
\hline Presentation*, n (\%) & & & 0.959 \\
\hline Supratentorial & $27(18.37)$ & $32(18.82)$ & \\
\hline Optic pathways & $32(21.77)$ & $37(21.76)$ & \\
\hline Infratentorial & $37(25.17)$ & $39(22.94)$ & \\
\hline Spinal & $34(23.13)$ & $43(25.29)$ & \\
\hline Multiple systems & $17(11.56)$ & 19 (11.18) & \\
\hline
\end{tabular}

\# value $<0.05$ was considered statistically significant.

Incomplete data.

DMT $=$ disease-modifying therapy, EDSS $=$ Expanded Disability Status Scale, $\mathrm{n}=$ number, RRMS $=$ relapsing-remitting multiple sclerosis, SD $=$ standard deviation .

Otherwise, no significant differences were found between DMT subgroups regarding sex, clinical presentation, mean disease duration or age at treatment beginning.

\subsection{Treatment persistence}

After one year of treatment, $16.34 \%$ of patients $(n=67)$ discontinued treatment, and after the total follow-up time $(6.07 \pm 3.98$ years) treatment was discontinued in $50.24 \%$, with a mean period for discontinuation of $39.80 \pm 35.73$ months.

\subsubsection{Treatment persistence based on clinical characteristics}

Clinical characteristics of the different groups of patients according to the persistence in the first DMT are presented in Table 2.

Patients who persisted on the first DMT were significantly older at treatment start than those who discontinued treatment (36.78 vs. 32.79, $p=0.02$ ), however, after multivariate analysis, age was not an independent predictor of treatment persistence.

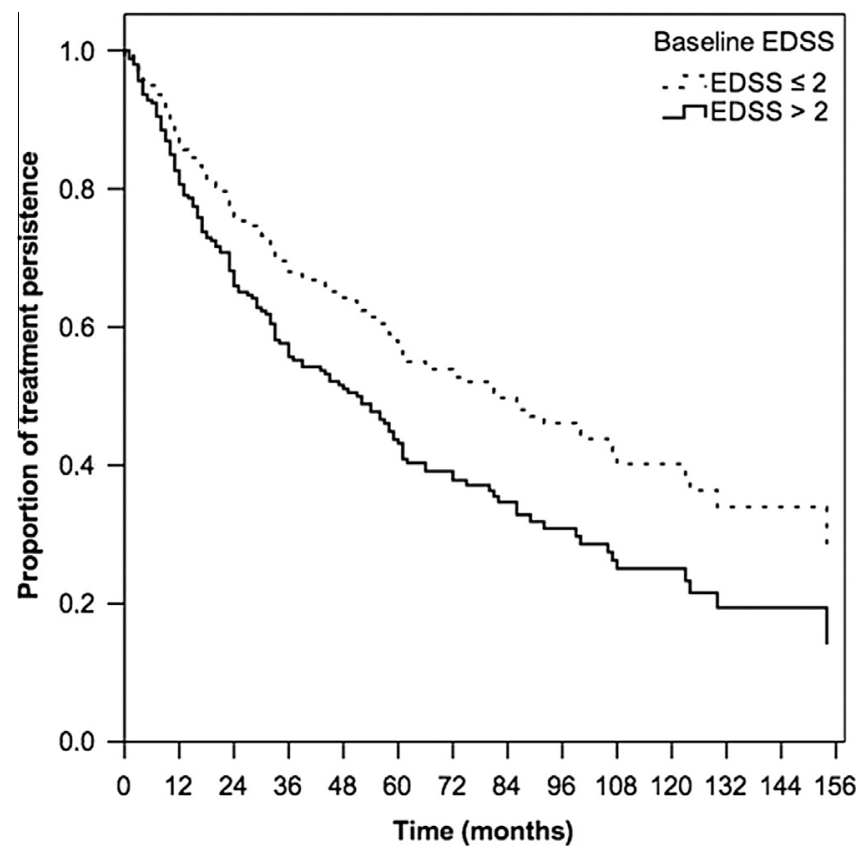

Fig. 1. Treatment persistence by baseline Expanded Disability Status Scale (EDSS)
Higher EDSS at baseline was an independent predictor of treatment discontinuation in multivariate analysis (hazard ratio [HR] $1.35, \mathrm{p}=0.002$ ). EDSS stratification using a cut-off value of 2.0 , revealed a higher risk of treatment discontinuation for patients with a baseline EDSS higher than 2.0 (HR 1.52, p = 0.012), as shown in Figure 1.

Sex and disease duration were not factors of treatment persistence in our population.

\subsubsection{Treatment persistence based on the first DMT}

The treatment persistence among the different DMT groups is presented in Figure 2 and Table 3.

After one year of treatment, the persistence rate was significantly lower for IFN $\beta-1 \mathrm{a} 22(69.64 \%)$ compared to the other DMT subgroups (Breslow Test $\mathrm{p}=0.023$ ) (Fig. 3). However, when considering the entire follow-up period, no significant differences were found between the DMT subgroups. After adjustment for baseline EDSS, treatment persistence on IFN- $\beta 1 \mathrm{a} 22$ was significantly lower than on IFN- $\beta 1$ aIM (HR $=0.48, \mathrm{CI} 0.38-0.81, \mathrm{p}=0.006$ ), without significant differences regarding the other DMT subgroups.

\subsection{Discontinuation}

A total of 206 patients discontinued treatment. The most common reason for treatment discontinuation was lack of efficacy

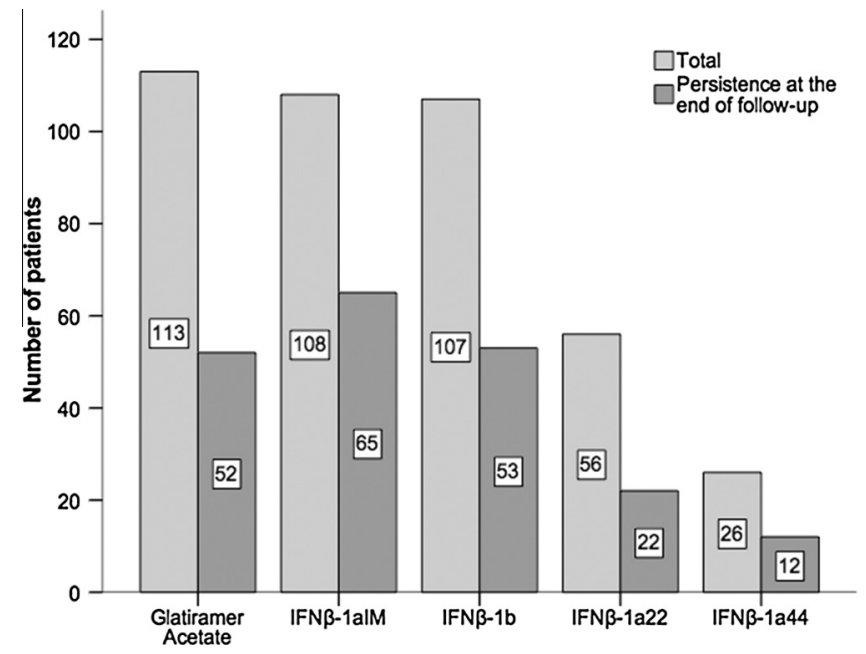

Fig. 2. Treatment persistence by disease-modifying therapies (DMT) subgroups IFN = interferon, IM = intramuscular. 


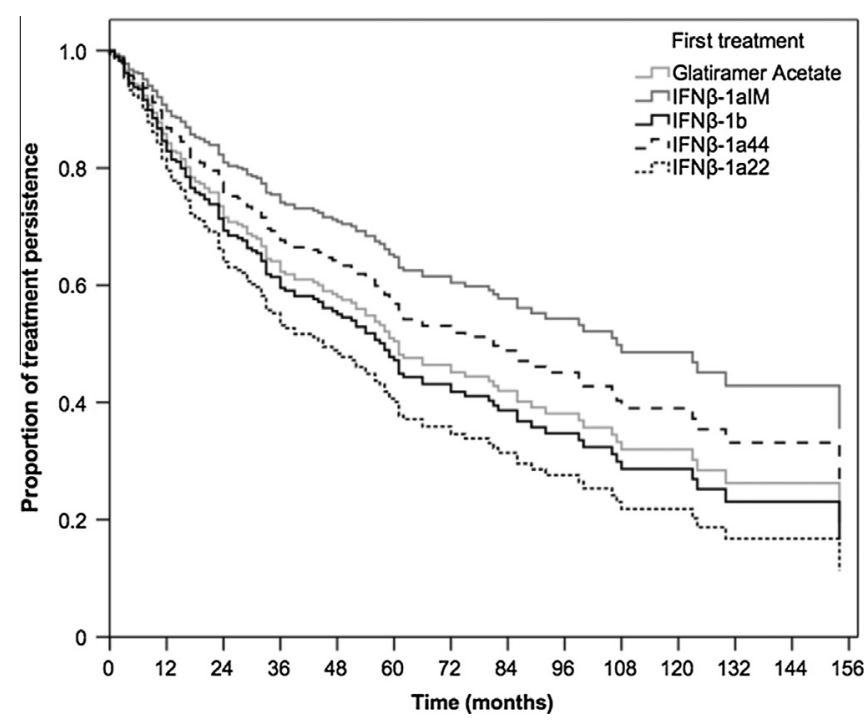

Fig. 3. Treatment persistence by disease-modifying therapy (DMT) subgroup adjusted for baseline Expanded Disability Status Scale (EDSS) IFN = interferon, IM = intramuscular.

(69.42\%), followed by adverse events (27.18\%) and pregnancy (3.40\%). No significant differences in the reasons for discontinuation were found between the DMT subgroups, as shown in Figure 4.

In most cases of lack of efficacy (89.51\%) discontinuation was due to clinical factors, relapses or disability progression, with the remaining cases being due to significant MRI lesion load increase (10.49\%).

The most common adverse event reported was systemic reactions such as flu-like syndrome, although local reactions such as exuberant inflammatory signs at injection site or lipoatrophy related to repeated injections were also frequent.

The treatments performed after stopping the initial DMT are presented in Table 4.

\section{Discussion}

This study evaluated the persistence in the first DMT in a large cohort of RRMS and CIS patients during a mean follow-up period of six years, and is one of the studies evaluating real-world treatment persistence with longer duration.

Although several possible predictors of treatment persistence were assessed, including sex, age at onset of RRMS, clinical presentation, disease duration, EDSS at baseline and the subgroup of DMT used, statistical significance was found only for baseline EDSS.

As previously observed in several studies, baseline EDSS showed to have a significant impact in treatment persistence, with a high EDSS score being a predictor of treatment discontinuation [6,8-11]. In fact, differences are evident even with a low cut-off score, with patients with baseline EDSS above 2 having 1.7-fold increased risk of discontinuing first treatment. This finding was independent of sex, age and disease duration, and is probably explained by the fact that treatment is more promptly switched in MS patients with higher clinical disability in order to prevent further disease progression.

Table 3

Treatment persistence in patients with relapsing-remitting multiple sclerosis commencing first-line treatment with DMT by DMT subgroup

\begin{tabular}{|c|c|c|c|c|c|c|c|}
\hline & $\begin{array}{l}\text { All DMT } \\
(\mathrm{n}=410)\end{array}$ & $\mathrm{GA}(\mathrm{n}=113)$ & $\begin{array}{l}\text { IFN } \beta-1 \mathrm{aIM} \\
(\mathrm{n}=108)\end{array}$ & $\begin{array}{l}\text { IFN } \beta-1 b \\
(n=107)\end{array}$ & $\begin{array}{l}\text { IFN } \beta-1 \mathrm{a} 22 \\
(\mathrm{n}=56)\end{array}$ & $\begin{array}{l}\text { IFN } \beta-1 \mathrm{a} 44 \\
(\mathrm{n}=26)\end{array}$ & $\begin{array}{l}\mathrm{p} \\
\text { value }\end{array}$ \\
\hline Follow-up time, years (SD) & $6.07( \pm 3.98)$ & $5.56( \pm 4.11)$ & $5.98( \pm 3.48)$ & $6.34( \pm 4.11)$ & $6.80( \pm 4.12)$ & $6.04( \pm 4.48)$ & 0.367 \\
\hline Treatment persistence after one-year, n (\%) & $343(83.66)$ & $94(83.19)$ & $98(90.74)$ & $89(83.18)$ & $39(69.64)$ & $23(88.46)$ & $0.014^{\#}$ \\
\hline DMT persistence, months (SD) & $53.02( \pm 42.93)$ & $\begin{array}{l}50.80 \\
( \pm 37.73)\end{array}$ & $56.57( \pm 43.06)$ & $50.17( \pm 44.04)$ & $51.54( \pm 48.60)$ & $62.85( \pm 46.92)$ & 0.322 \\
\hline $\begin{array}{l}\text { Treatment persistence at the end of follow-up, } \\
n(\%)\end{array}$ & $204(49.76)$ & $52(46.02)$ & $65(60.19)$ & $53(49.53)$ & $22(39.29)$ & $12(46.15)$ & 0.094 \\
\hline
\end{tabular}

\# p value $<0.05$ was considered statistically significant.

DMT = disease-modifying therapy, GA = glatiramer acetate, IFN = interferon, $\mathrm{IM}=$ intramuscular, $\mathrm{n}=$ number, $\mathrm{SD}=\mathrm{standard}$ deviation.

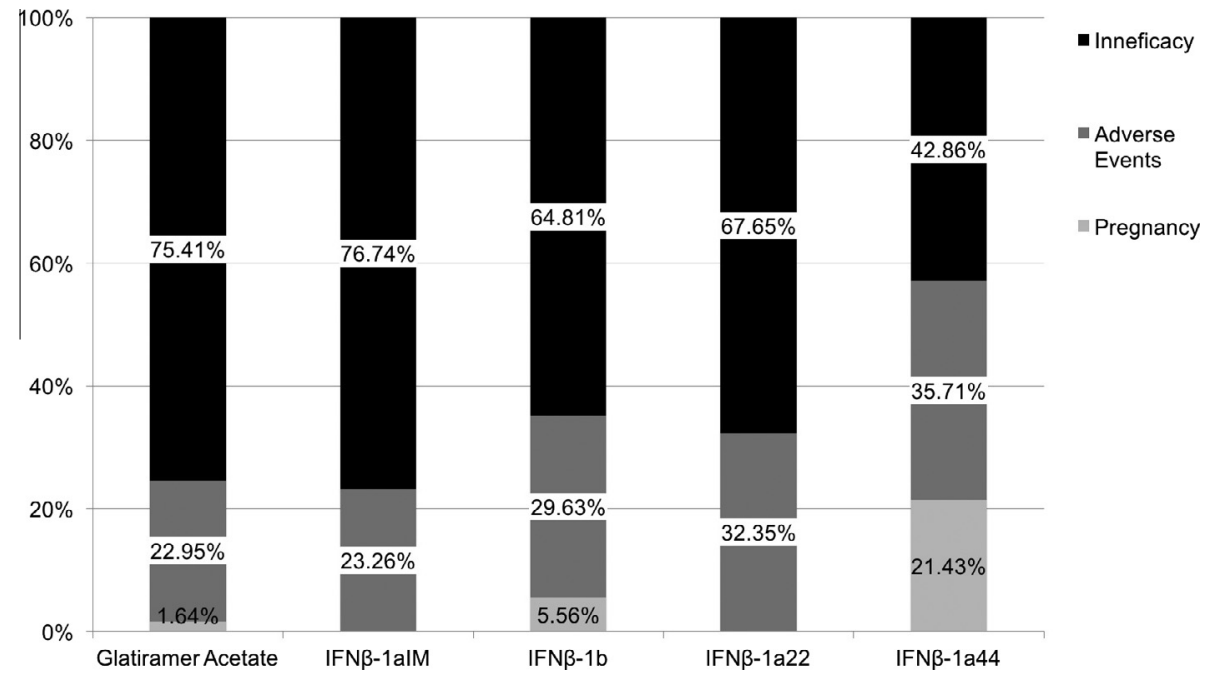

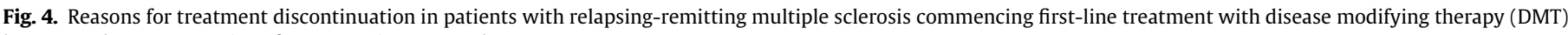
by DMT subgroup. IFN = interferon, IM = intramuscular. 
Table 4

Subsequent therapy after stopping the initial DMT in patients with RRMS commencing first-line treatment with DMT

\begin{tabular}{|c|c|c|}
\hline Initial DMT & Subsequent DMT & $\mathrm{n}(\%)$ \\
\hline IFN $\beta-1 \mathrm{a} 22$ & $\begin{array}{l}\text { IFN } \beta-1 \mathrm{a} 44 \\
\text { GA } \\
\text { Immunosuppression } \\
\text { IFN } \beta-1 \mathrm{~b} \\
\text { IFN } \beta \text {-1aIM } \\
\text { Natalizumab } \\
\text { Fingolimod }\end{array}$ & $\begin{array}{l}12(35.29) \\
8(24.53) \\
4(11.76) \\
3(8.82) \\
3(8.82) \\
2(5.88) \\
1(2.94)\end{array}$ \\
\hline Glatiramer Acetate & $\begin{array}{l}\text { IFN } \beta-1 \mathrm{~b} \\
\text { Immunosuppression } \\
\text { IFN } \beta-1 \mathrm{aIM} \\
\text { Natalizumab } \\
\text { Fingolimod } \\
\text { IFN } \beta-1 \mathrm{a} 22 \\
\text { IFN } \beta-1 \mathrm{a} 44 \\
\text { None }\end{array}$ & $\begin{array}{l}19(31.15) \\
11(18.03) \\
9(14.75) \\
9(14.75) \\
6(9.84) \\
4(6.56) \\
1(1.64) \\
2(3.28)\end{array}$ \\
\hline IFN $\beta-1 \mathrm{a} 44$ & $\begin{array}{l}\text { Natalizumab } \\
\text { GA } \\
\text { IFN } \beta-1 \mathrm{a} 22 \\
\text { IFN } \beta-1 \mathrm{aIM} \\
\text { None }\end{array}$ & $\begin{array}{l}4(28.57) \\
3(21.43) \\
3(21.43) \\
2(12.29) \\
2(12.29)\end{array}$ \\
\hline IFN $\beta-1 b$ & $\begin{array}{l}\text { Natalizumab } \\
\text { Immunosuppression } \\
\text { GA } \\
\text { Fingolimod } \\
\text { IFN } \beta \text {-1aIM } \\
\text { IFN } \beta-1 \mathrm{a} 44 \\
\text { None }\end{array}$ & $\begin{array}{l}16(29.63) \\
14(27.78) \\
9(16.67) \\
7(12.96) \\
3(5.56) \\
2(3.70) \\
3(5.56)\end{array}$ \\
\hline IFN $\beta-1$ aIM & $\begin{array}{l}\text { IFN } \beta-1 b \\
\text { GA } \\
\text { Natalizumab } \\
\text { Immunosuppression } \\
\text { Fingolimod } \\
\text { IFN } \beta-1 \mathrm{a} 22 \\
\text { IFN } \beta-1 \mathrm{a} 44\end{array}$ & $\begin{array}{l}11(25.58) \\
8(18.60) \\
7(16.28) \\
7(16.28) \\
5(11.63) \\
3(6.98) \\
2(4.65)\end{array}$ \\
\hline
\end{tabular}

Note: Immunosuppression includes cyclophosphamide, mitoxantrone, azathioprine and mycophenolate mofetil.

DMT $=$ disease-modifying therapy,$\quad G A=$ glatiramer acetate,$\quad I F N=$ interferon $\mathrm{IM}=$ intramuscular, $\mathrm{n}=$ number.

Despite not being statistically significant in multivariate analysis, a trend to higher rates of treatment discontinuation was found in younger patients, which is in accordance with previous reports [10]. A more active relapsing disease in early stages of the disease with indication to switch to more effective treatments may explain this finding.

The DMT used was also a predictor of treatment discontinuation in our population, even after adjusting for baseline EDSS, with a higher discontinuation rate found for IFN $\beta-1 \mathrm{a} 22$, which was also switched earlier than the other DMTs. This finding may be a bias, as in our Clinic there is a low threshold to switch patients from IFN $\beta-1 \mathrm{a} 22$ to the higher dosage formulation available, IFN $\beta-1 \mathrm{a} 44$, as occurred in $36.4 \%$ of these patients. This has not been reported in previous studies, as the two formulations of subcutaneous IFN $\beta-1 \mathrm{a}$ are usually not discriminated $[9,10]$. Higher persistence rates were observed with IFN $\beta$-1aIM, which may be related with a higher patient adherence to a treatment with a lower frequency of administration, as reported in a large study addressing treatment adherence to injectable therapies [12].

Unlike several previous reports, we found no association between female sex and treatment discontinuation $[6,8,9,13]$.

Overall, $16.3 \%$ of patients discontinued treatment during the first year of treatment, and 50.2\% discontinued treatment during the total follow-up period, with a mean time for discontinuation of treatment of 39.8 months. In most cases, treatment was switched due to lack of efficacy of the DMT being used.
The discontinuation rate due to adverse events is variable among the available studies, with rates reported ranging from $14.7 \%$ to $58 \%[5-7,10,14]$. In our population the discontinuation rate due to adverse events was relatively low (27.18\%). This may be explained by the fact that, in our clinic, before treatment beginning, qualified nurses explain to the patients the best way of managing the injection devices and providing the injection and also correct misuse of the device during treatment in cases of local side effects related to the injections. Additionally, symptomatic treatments, such as nonsteroidal anti-inflammatory drugs and paracetamol, are routinely used by physicians in order to minimize systemic side effects.

This study presents some limitations, including the different sample size for each DMT subgroup and being a retrospective study, with incomplete data regarding causes of treatment discontinuation and baseline annualized relapse rate in a significant number of patients.

\section{Conclusions}

Treatment persistence is an important indicator of effectiveness and the identification of predictors to discontinuation is important in clinical practice, as other therapies are currently available. In our population, approximately $15 \%$ of patients discontinued first DMT after 1 year and $50 \%$ in the total follow-up time. Higher baseline EDSS was the only independent predictor of treatment discontinuation as the threshold for treatment switch is lower in patients with more disability. The DMT used was also a predictor of treatment persistence with higher persistence rates for DMT with lower frequency of administration. The most common reason for treatment discontinuation was lack of efficacy, clinically or radiologically determined, in all DMT subgroups.

\section{Conflicts of Interest/Disclosures}

Dr. Sónia Batista has received grant support from Biogen and speakers bureau fees from Biogen, Novartis and Merck. Dr. Carla Nunes, Dr. Carmo Macário and Dr. Lívia Sousa have received speakers bureau fees and have been advisory board members for Biogen Idec $^{\circledR}$, Novartis ${ }^{\circledR}$, Teva $^{\circledR}$, Bayer $^{\circledR}$, Genzyme $^{\circledR}$ and Merck $^{\circledR}$. Inês Correia, Inês Brás Marques, Mário Sousa and Luís Cunha declare that they have no financial or other conflicts of interest in relation to this research and its publication.

\section{References}

[1] Interferon beta-1b is effective in relapsing-remitting multiple sclerosis. I. Clinical results of a multicenter, randomized, double-blind, placebo-controlled trial. IFNB Multiple Sclerosis Study Group. Neurology 1993:43:655-61.

[2] Randomised double-blind placebo-controlled study of interferon beta-1a in relapsing/remitting multiple sclerosis. PRISMS (Prevention of Relapses and Disability by Interferon beta-1a Subcutaneously in Multiple Sclerosis) Study Group. Lancet 1998:352:1498-504.

[3] Jacobs LD, Cookfair DL, Rudick RA, et al. Multiple Sclerosis Collaborative Research Group (MSCRG): intramuscular interferon beta-1a for disease progression in relapsing multiple sclerosis. Ann Neurol 1996;39:285-94.

[4] Johnson KP, Brooks BR, Cohen JA, et al. Copolymer 1 reduces relapse rate and improves disability in relapsing-remitting multiple sclerosis: results of a phase III multicenter, double-blind placebo-controlled trial. The Copolymer 1 Multiple Sclerosis Study Group. Neurology 1995;45:1268-76.

[5] O’Rourke KE, Hutchinson M. Stopping beta-interferon therapy in multiple sclerosis: an analysis of stopping patterns. Mult Scler 2005;11:46-50.

[6] Río J, Porcel J, Téllez N, et al. Factors related with treatment adherence to interferon beta and glatiramer acetate therapy in multiple sclerosis. Mult Scler 2005;11:306-9.

[7] Ruggieri RM, Settipani N, Viviano L, et al. Long-term interferon-beta treatment for multiple sclerosis. Neurol Sci 2003;24:361-4.

[8] Tremlett HL, Oger J. Interrupted therapy: stopping and switching of the betainterferons prescribed for MS. Neurology 2003;61:551-4 
[9] Meyniel C, Spelman T, Jokubaitis VG, et al. Country, sex, EDSS change and therapy choice independently predict treatment discontinuation in multiple sclerosis and clinically isolated syndrome. PLoS One 2012;7:e38661.

[10] Jokubaitis VG, Spelman T, Lechner-Scott J, et al. The Australian Multiple Sclerosis (MS) immunotherapy study: a prospective, multicentre study of drug utilisation using the MSBase platform. PLoS One 2013;8:e59694.

[11] Sá MJ, de Sá J, Sousa L. Relapsing-remitting multiple sclerosis: patterns of response to disease-modifying therapies and associated factors: a national survey. Neurol Ther 2014;3:89-99.
[12] Devonshire V, Lapierre Y, Macdonell R, et al. The Global Adherence Project (GAP): a multicenter observational study on adherence to disease-modifying therapies in patients with relapsing-remitting multiple sclerosis. Eur J Neurol 2011;18:69-77.

[13] Reynolds MW, Stephen R, Seaman C, et al. Persistence and adherence to disease modifying drugs among patients with multiple sclerosis. Curr Med Res Opin 2010;26:663-74.

[14] Portaccio E, Zipoli V, Siracusa G, et al. Long-term adherence to interferon therapy in relapsing-remitting multiple sclerosis. Eur Neurol 2008;59:131-5. 